\title{
EL "PATITO FEO" EN LA ALAMEDA: LA ESTANCIA DE HANS CHRISTIAN ANDERSEN EN MÁLAGA
}

\author{
Francisco García Gómez
}

\begin{abstract}
RESUMEN
En este artículo abordamos la estancia de Hans Christian Andersen en Málaga en 1862, a través de los recuerdos que incluye en su libro Viaje por España (I Spanien), publicado en 1863. En él nos deja una serie de impresiones en las que se interesa, más que por los monumentos, por la vida en la ciudad y por sus gentes.
\end{abstract}

\begin{abstract}
In this article we tackle the stay of Hans Christian Andersen in Málaga in 1862 through his memories included in his book In Spain (I Spanien), published in 1863. In it he leaves us some impressions in which he shows his interest in the city life and its people more than in the monuments.
\end{abstract}

"En ninguna otra ciudad española he llegado a sentirme tan dichoso y tan a gusto como en Málaga. Un propio modo de vivir, la naturaleza, el mar abierto, todo cuanto para mí es vital e imprescindible lo hallé aquí; y algo todavía más importante: gente amable"1.

Estas palabras de Hans Christian Andersen (1805-1875) constituyen sin duda las más hermosas de todas las escritas por los numerosos viajeros extranjeros que visitaron Málaga a lo largo del siglo XIX. Ninguno de los que más disfrutaron de su estancia en esta ciudad (que fueron bastantes, aunque también hubo quienes abominaron de ella) se mostró tan cómodo como el escritor danés ${ }^{2}$. Y por

1. Todas las citas de Andersen proceden de la traducción de I Spanien por Marisa Rey: ANDERSEN, H.C.: Viaje por España. Madrid 2005, 115.

2. Hay muchas traducciones y estudios acerca de los escritos de los viajeros europeos sobre Málaga. De entre los libros centrados exclusivamente en esta ciudad, citaremos: 
la sinceridad que emana de sus frases, el autor de La reina de las nieves nos demuestra que no era precisamente un cuentista... Coincidiendo con la celebración en 2005 del segundo centenario de su nacimiento, que incluyó varios actos de homenaje en Málaga, nos proponemos comentar un texto que dice mucho sobre la ciudad y sus habitantes, pero también, qué duda cabe, sobre el carácter y la mentalidad de tan magnífico autor, que trasciende con creces su tópica clasificación como escritor para niños. La percepción de la ciudad que el ilustre danés nos ofrece será el objeto de estudio de este artículo.

El creador de El ruiseñor fue un infatigable viajero. A partir de que en 1831 realizara su primera visita al extranjero, en concreto a Alemania y Suiza, Andersen viajó en veintinueve ocasiones fuera de Dinamarca ${ }^{3}$. Italia, Francia, Suecia, Noruega, Holanda, Gran Bretaña, Austria, Grecia, Turquía o Portugal fueron otros de los países que conoció, casi siempre bien a fondo. El propio escritor nos ofrece una de las claves de esta pulsión viajera:

"Es viajando que la vida se enriquece y tiene razón de ser, pues cuando se viaja uno no se nutre, como el pelícano, con la propia sangre sino con las dádivas de la Naturaleza"4.

Aunque él no lo admite directamente, sus viajes también tenían un destacado componente de huida de Dinamarca, desde el momento en que Andersen solía estar más reconocido fuera de sus fronteras ${ }^{5}$. Mientras que en su país siempre fue visto -y él así lo sintió hasta lo obsesivo- como un advenedizo social, como un desarraigado (de hecho, nunca tuvo domicilio propio), a pesar de sus relaciones con las élites y de que pronto se le reconoció su calidad artística (más allá de duras reseñas de determinados sectores de la crítica), en

GÁMIR SANDOVAL, A.: Algunos viajeros del siglo XIX ante Málaga. Granada 1962; MAJADA NEILA, J.: Viajeros románticos en Málaga. Salamanca 1986; y KRAUEL, B.: Viajeros británicos en Málaga (1760-1855). Málaga 1988. Nosotros ya hemos publicado en esta revista una serie de artículos sobre la percepción que tales viajeros ofrecen del urbanismo y la arquitectura malagueñas: GARCÍA GÓMEZ, F.: "Descubriendo la ciudad (I): El urbanismo malagueño según los viajeros extranjeros del siglo XIX", Baetica 17, 1995, 7-29; "Descubriendo la ciudad (II). La arquitectura malagueña según los viajeros extranjeros del siglo XIX: la Catedral”, Baetica 18, 1996, 7-16; y "Descubriendo la ciudad (III): La arquitectura malagueña según los viajeros extranjeros del siglo XIX: los restos musulmanes", Baetica 19 (I), 1997, 41-57.

3. NIELSEN, E.: Hans Christian Andersen. Copenhague 1983, 38-43. "En total, Andersen pasó nueve años de su vida viajando por el extranjero". MYLIUS, J. de: "Andersen, un danés universal", H.C. Andersen, Salamanca 2005, 14.

4. Cit. en NIELSEN, E.: op. cit., 41.

5. LORENZO, M.P.: "El cuento de su vida", prólogo a ANDERSEN, H.C.: El cuento de mi vida. Madrid 2005, 29. 
los otros lugares desaparecían los prejuicios sociales, para atender exclusivamente a los factores literarios en su valoración. Además, en esos países podía dar rienda suelta a su exagerada vanidad, tratando con -y normalmente siendo agasajado por- las más ilustres personalidades, tanto gobernantes y aristócratas como escritores y artistas. Así podía regresar a Copenhague cargado de autoestima con la que hacer frente a las críticas de sus compatriotas, que tanto herían su hipersensibilidad. Personalidad contradictoria, oscilante entre lo ingenuo y lo oportunista, en el fondo Andersen fue siempre un acomplejado a causa de sus humildes orígenes, un trauma en sus obsesiones de ascenso social $^{6}$. El escritor se vio siempre a sí mismo como un "patito feo", que una vez convertido en cisne recibía los elogios de la gente más importante; si bien, al contrario que su personaje, nunca superó sus problemas de identidad. Incluso su autobiografía lleva un título bien significativo: El cuento de mi vida (1855), cuyo discurso central es la demostración de que el discurrir de su existencia respondió a un perfecto plan de la divinidad para permitirle ascender de la pobreza a la gloria, lo que le lleva inevitablemente a la justificación egocéntrica, la autoexaltación (enumera con orgullo a todos los grandes personajes que conoció) y algunas mixtificaciones idealizadoras (habituales, por otra parte, en todas las memorias). Rasgos de su psicología que nos resultarán de suma utilidad para comprender su relación con España.

Pese a todo, es innegable que sus viajes le suponían un enriquecimiento espiritual, que además daba sus frutos en unos excelentes libros, desde que en el mismo año de su primera salida escribiera Sombras chinescas de un viaje a Harzen y a la Suiza sajona, y hasta que en 1868 publicara el relato de su Visita a Portugal realizada dos años antes. De ellos, los mejores son El bazar de un poeta (1842) y En Suecia (1851). Mientras que en el primero recoge las experiencias de un poco convencional viaje -para la época- por Alemania, Austria, Italia, Malta, Grecia y Turquía, incluyendo una travesía por el Danubio, realizado entre 1840 y 1841, en el segundo relata su exploración de zonas poco conocidas del país escandinavo durante 1849.

Entre el 4 septiembre y el 23 diciembre de 1862 Andersen, que tenía 57 años, visitó España en compañía del joven Jonas Collin, de 227, hijo de su amigo Edvard y nieto de Jonas Collin, el más destacado mentor del escritor, un rico financiero que, en su cargo de director del Teatro Real de Copenhague,

6. Andersen es un escritor cuya obra es imposible comprender en profundidad sin atender a su vida. Aparte de en los libros citados, análisis de su personalidad encontramos en: ROSENVINGE, T.: Hans Christian Andersen. Una vida de cuento. Madrid 2005; MYLIUS, J. de: "Unas breves pinceladas biográficas", H.C. Andersen, 19-31; y REY, M.: "Hans Christian Andersen: su obra literaria y su tradición cultural", epílogo a Viaje por España, 331-364.

7. ANDERSEN, H.C.: Viaje..., 14, n. 1. 
resultó fundamental para su carrera. Ambos visitaron, por este orden, Barcelona, Valencia, Alicante, Elche, Murcia, Cartagena, Málaga, Granada, Gibraltar, Cádiz, Sevilla, Córdoba, Madrid, Toledo, Burgos y San Sebastián, además de otras poblaciones menores. Es decir, entraron por La Junquera y salieron por Irún. El relato de su viaje, que también incluyó una visita a Tánger entre sus estancias en Gibraltar y Cádiz, lo publicó en Dinamarca en 1863, bajo el título I Spanien (En España, aunque se ha traducido como Viaje por España). Al año siguiente aparecieron las traducciones alemana, editada en Leipzig, e inglesa, en Londres, los dos países en los que Andersen gozó en vida de un mayor éxito. Desde hacía varias décadas, el autor de El traje nuevo del emperador ya era un escritor famoso en toda Europa, aunque, luego lo comentaremos, no así en España. La segunda edición danesa se publicó en 1878, a los tres años de su fallecimiento, y cuando ya era reconocido como una de las dos principales glorias literarias de Dinamarca. La otra es el filósofo Søren Kierkegaard, en gran medida su espíritu opuesto.

El creador de Las zapatillas rojas permaneció en Málaga varios días entre finales de septiembre y finales de octubre, interrumpidos por una estancia de quince días en Granada. En su relato de viajes apenas se incluyen fechas, de manera que no sabemos con exactitud en qué momento de septiembre arribó al puerto de Málaga en el vapor "Non Plus Ultra", procedente de Cartagena. Aunque se puede hacer un cálculo aproximado y situarlo hacia el 27 ó 28 de dicho mes. Lo que sí indica es la fecha de su regreso, ahora en diligencia desde la ciudad de la Alhambra: el 22 de octubre. Las otras fechas podemos calcularlas gracias a indicios indirectos que hemos corroborado acudiendo a la prensa local. La primera fase en Málaga parece que fue la más larga, en torno a una semana: dice que se marchó la tarde en que asistió a los toros, y por $E l$ Avisador Malagueño sabemos que dicho espectáculo tuvo lugar el domingo 5 de octubre 8 . A la vuelta estuvo seis días: tomó para Gibraltar el vapor "Ville de Paris" (él escribe "París"), que partió la tarde del martes 28 de octubre 9 . En total, el escritor permaneció en la ciudad cerca de quince días.

Como puede comprobarse, Andersen llegó a Málaga de las dos maneras en que podía hacerse en el XIX, por mar y por tierra, con lo que pudo disfrutar de una doble perspectiva de la ciudad. Una localidad que, por su emplazamiento y orografía, ofrece al viajero vistas panorámicas sumamente atracti-

8. También por este periódico sabemos que viajó con la compañía La Madrileña, cuyos carruajes partían para Granada los días impares de ese mes. El Avisador Malagueño, 1-101862, 4.

9. Dicho barco, bajo el mando del capitán Aude, debía partir a las 8 de la mañana. El Avisador Malagueño, 24-10-1862, 4. Sin embargo, Andersen indica que por causa de una tormenta llegó con retraso, por lo que se hizo a la mar por la tarde. ANDERSEN, H.C., Viaje..., 183. 
vas, en términos de pintoresquismo. El autor de La sombra así lo reconoce en su texto, sobre todo a su retorno por la carretera de los Montes, desde la que divisa una ciudad que ya le resulta familiar:

"Irrumpió el sol; el mar se extendía brillante y azul, las blancas casas de chatos tejados, la imponente catedral de Málaga y la elevada fortaleza mora recortábanse contra el mar y el cielo. Ya veíamos el cauce seco del río Guadalmedina a lo lejos (...). Era como regresar a casa: todo nos resultaba conocido y en el hotel nos recibieron como a viejos amigos" 10 .

Palabras que constituyen la plasmación de un alegre reencuentro. Y es que desde su llegada, cuando en su descripción del bullicio portuario vio presagios favorables en la cantidad de barcos daneses fondeados, Andersen sintió una inequívoca fascinación por Málaga. Él mismo explica las razones: modo de vida, clima, mar, alegría y amabilidad de la gente. Ya entonces se reconocían en la ciudad unos valores que un siglo después la convertirían en la capital de una de las costas con mayor afluencia turística de España. Por supuesto, no podía hacer referencia a unos posibles hitos patrimoniales por los que Málaga, para ser sinceros, nunca ha destacado (apreciación evidente que no debe ser malinterpretada): en este sentido, fue Sevilla la ciudad española que más le impactó, incluyendo el tópico de que sería perfecta de estar bañada por el $\operatorname{mar}^{11}$. De todas formas, la monumentalidad no era lo que el escritor más demandaba de un lugar, aunque eso no significaba desinterés por su parte. Como es lógico en un espíritu hipersensible como el suyo, muestra atracción por el arte y la arquitectura, y en todas las ciudades por las que pasa visita lo que en aquel tiempo se consideraba digno de conocer. Los mejores ejemplos son los amplios espacios que dedica a la descripción de la Alhambra o de los Alcázares de Sevilla. Sin embargo, con frecuencia tales comentarios artísticos están extraídos de libros o guías, e incluso incurren en errores, como el considerar creación musulmana los Alcázares hispalenses. De hecho, Andersen nunca demostró grandes conocimientos en historia del arte.

Debido a esas lagunas estéticas, y también por supuesto a su propio temperamento, en sus relatos viajeros suele preferir el paisaje y las gentes de un lugar, muy por delante de unos monumentos cuya inclusión a veces no es más que un tributo de peaje casi obligatorio en cualquier libro de ese género en el XIX. En su volumen dedicado a nuestro país, un caso sintomático de dichas prioridades es su comentario acerca de Orihuela: 
"Admito haber visto los monumentales edificios de la villa, su grandioso Cuartel de Caballería, el Palacio del Arzobispo y la catedral; mas no guardo el menor recuerdo de todo ello. En cambio, la taberna donde comimos aquel mismo día no la olvidaré jamás"12.

Para pasar inmediatamente a dedicar más de una página a la descripción de tan pintoresco lugar. Sin embargo, esa frecuente opción por la estampa vital, por el tipismo, por el color local, no significa caer en la exageración costumbrista. Aunque hay bastantes páginas que recogen los tópicos españoles (¿hay algún viajero capaz de evitarlos?), el padre de La sirenita sabe escapar, gracias a las virtudes de su pluma, a sus dotes de estilista, de ese costumbrismo mecánico, hueco y bobo, que constituye una de las principales trampas (y lacras) de la, por otra parte, esplendorosa literatura decimonónica. Por supuesto, su visión eminentemente poética del mundo, su capacidad de advertir la belleza de los pequeños detalles, además de su sagacidad de observación y el fundamental aderezo de la ironía, le permiten captar en pocas pinceladas la esencia de un lugar. Sensibilidad y humor van de la mano en las mejores páginas de Viaje por España. Es decir, justo los valores estéticos que convierten la mayor parte de sus cuentos en algunas de las cimas de la narración breve de todos los tiempos. Como Poe, Maupassant o Borges, el danés es uno de esos escritores que ofrecen lo mejor de sí en las distancias cortas.

Su capítulo y medio dedicado a Málaga (su primera estancia aparece reflejada en el octavo capítulo, titulado "Málaga", y la segunda en el décimo, "De Granada a Gibraltar") es un magnífico exponente de lo que venimos diciendo. Comenzaremos por los aspectos arquitectónicos, y por el principal monumento de la ciudad: la Catedral. Andersen la despacha en una frase:

"A través de tortuosas callejuelas se alcanza la imponente catedral de Málaga, que se asemeja a una enorme montaña esculpida en el mármol, cuya grandeza domina la ciudad entera"13.

Inmediatamente después comenta las magníficas vistas que se observan desde su torre. De manera que, sin decirnos casi nada de su arquitectura, ni referirse al interior, el edificio se convierte en una simple atalaya desde la que divisar el panorama. La metáfora poética y la estampa paisajista se anteponen a la minuciosa descripción constructiva, por otra parte sin menoscabo del reconocimiento de sus valores estéticos. No olvidemos que Andersen no está escribiendo una guía, sino unas memorias viajeras. Es lo que lo distingue de un

12. Ibídem, 82.

13. Ibídem, 113. 
Laborde o un Richard Ford. Los criterios selectivos de unos y de otros nunca pueden ser los mismos. Sin embargo, pese a la parquedad de estas palabras, de su lectura se desprende que la Catedral malacitana es un monumento digno de ser visitado. Más adelante vuelve a recurrir a la metáfora en una nueva cita del templo: desde una villa en los montes divisará la ciudad, "cuya imponente catedral recordaba una inmensa arca en medio de un mar petrificado y blanco de espuma" 14 .

Algo similar sucede con el espacio dedicado a "un monasterio que antiguamente fue visitado por Isabel la Católica, quien hizo allí donación de la talla de madera de un santo" muy milagroso ${ }^{15}$ : dado que Andersen lo vio cuando pasaba por el camino a la espalda del Cementerio Inglés (es decir, el conocido como Camino Nuevo, que rodea los montes de Sancha y Gibralfaro), parece que se trata del antiguo convento de los mínimos, el santuario de Nuestra Señora de la Victoria, aunque está claro que incurre en errores históricos, ya que en realidad se erigió sobre el campamento de Fernando y la talla donada que cita debe ser la Virgen de la Victoria. De su paso junto a él resalta sobre todo el sentimiento de misteriosa soledad que le produjo a la luz del crepúsculo, aunque hay que indicar que tras la desamortización actuaba como Hospital Militar.

Si bien el autor de El firme soldado de plomo admiraba la arquitectura cristiana de España, incluso con esa mezcla de extrañeza y fascinación habitual en los protestantes, a lo largo de su libro su principal objeto de interés lo constituyen los vestigios musulmanes. En este sentido, pese a la tardía fecha de su viaje, Andersen llega equipado con la mentalidad romántica, la predominante en casi todos los extranjeros que recorrieron España en el XIX. De hecho, la mitad del libro está dedicada a Andalucía, región metonímica por excelencia de este país hasta no hace demasiado tiempo. Y Andalucía significaba, sobre todo, la posibilidad de disfrutar de lo exótico y oriental sin necesidad de salir de Europa. La huella de Al-Andalus era lo prioritario para todos ellos. Y para un fabulador como el danés, también. De ahí que la Alhambra sea el monumento español al que más páginas dedica, incluyendo un acertado comentario arquitectónico.

Sin embargo, curiosamente, en Málaga no visitó ni la Alcazaba ni Gibralfaro. Al castillo sólo lo cita en su visión panorámica desde el mar ("su prominente Gibralfaro, la antigua y resistente fortaleza árabe" ${ }^{16}$ ), mientras que la Alcazaba ni siquiera es nombrada. Es extraño que no entrara en ninguno de los dos, en especial el castillo, excursión obligada para casi todos los viajeros 
del XIX, tanto por motivos artísticos como paisajísticos ${ }^{17}$. En cambio, la Alcazaba, convertida desde el XVIII en un barrio de casas populares que alteraban por completo su arquitectura originaria, despertaba mucho menos interés que Gibralfaro, por lo que puede entenderse que Andersen no la pisara (o, al menos, que no dejara constancia escrita al no llamarle la atención).

El espacio dedicado a los monumentos musulmanes lo ocupan las Atarazanas y dos ejemplos de arquitectura doméstica. En ambos casos cae en errores más o menos comprensibles y, por supuesto, totalmente disculpables. En el caso del viejo arsenal naviero, que sería derribado ocho años más tarde de su visita, Andersen lo confunde con las antiguas murallas de Málaga, y a su monumental puerta con una de las de acceso a la ciudad: tampoco yerra en exceso, pues las Atarazanas se fundían con el recinto fortificado en esa zona.

Por otro lado se encuentran las dos casas que visitó también en sus cercanías, situadas en la misma calle y a las que clasifica como morunas. Realmente, en la segunda mitad del XIX ya quedaban en la ciudad muy pocos restos del pasado doméstico musulmán. De manera que el adjetivo moruno aplicado a tales casas también podría ser interpretado en el sentido de mudéjar, un concepto desconocido por Andersen. Cuando describe sus espacios y decoraciones, parece que se trata de reformulaciones cristianas de la arquitectura islámica, construcciones de finales del XV o ya del XVI; todo lo más, antiguas viviendas musulmanas muy transformadas en siglos sucesivos. El caso es que sus palabras constituyen importantes testimonios de los vestigios que aún se mantenían de la arquitectura doméstica mudéjar, y que muy pronto desaparecerían. Además de indicar las alteraciones de sus fisonomías primitivas (una de ellas albergaba entonces una ferretería), recoge su distribución en torno a patios columnados, la presencia de artesonados de madera (algunos dorados y policromados), una cúpula, ajimeces y hasta un decadente jardín en una de ellas $^{18}$.

Por encima de las descripciones arquitectónicas, el escritor resalta el ambiente que en ellas se respiraba, su quietud detenida en el tiempo, dando paso a las evocaciones del pasado musulmán que le sugerían, como las especulaciones sobre sus antiguos habitantes. Fiel al sentimiento romántico, el autor de $L a$ princesa y el guisante prioriza, al abordar un edificio, la asociación de ideas y la sinestesia al mero recuento formal. En este sentido, suele coincidir con la mayor parte de los escritores de viajes decimonónicos. Salvo con la particula-

17. Acerca del impacto de los monumentos árabes de Málaga sobre los extranjeros: GARCÍA GÓMEZ, F.: "Descubriendo la ciudad (III)..."

18. Quizás una de las dos podría tratarse de los restos de baños árabes citados por Benito Vilá en su guía, situados en calle Santo Domingo y entonces ocupados por los almacenes de Hernández y Sedeño. Según describe, se conservaba una bóveda sostenida por arcos sobre columnas y un pozo. VILÁ, B.: Guía del viajero en Málaga. Málaga 1861, 67-8. 
ridad de que en este caso, además, se trata de un magnífico literato, uno de los mejores extranjeros que visitaron Málaga en el Ochocientos. Precisamente, esa poesía ensoñadora es lo que esperábamos de Andersen, y si se hubiera limitado a la fría acumulación de datos nos habría defraudado (reconocemos que nuestra vena lírica traiciona a nuestra formación de historiador):

"Mientras paseaba por aquí, antojábaseme que la nubecilla de calor del sol era un velo mágico que, extendido sobre el añoso jardín tapiado, hacía dormir a todo. Pero en cuanto se alzase el velo, se rompería el hechizo; los chorros del agua tornarían a salpicar en las pilas; los árboles y flores, más frescos que nunca, se recobrarían en su sitio; los moros y las moras se levantarían de su sueño de muerte para volver a vivir y a laborar" ${ }^{\prime 9}$.

El lugar de Málaga que más le fascinó fue el Cementerio Inglés. Y las páginas que dedica a tan romántico lugar resultan sintomáticas de la percepción anderseniana, recurriendo incluso a leyendas escandinavas (en ese sentido es evidente la vinculación de Andersen con el romanticismo alemán, con sus admirados Hoffmann, Tieck y Chamisso), para así erigirse en uno de los más bellos pasajes de todo el libro. Reproduzcamos algunas de sus frases impregnadas tanto de espíritu sublime como de fina ironía:

"En los países nórdicos cuentan de profundos y oscuros lagos que, de un modo extraño, atraen a la gente hacia sí, forzando finalmente al melancólico a arrojarse a su fascinadora profundidad. Algo de esta extraña fuerza ejerció el cementerio protestante de Málaga sobre mí. Llegué a comprender por qué un lunático inglés se había quitado la vida para que lo enterrasen en este lugar. Gracias a Dios, yo no soy un lunático, sino que siento todavía deseos de ver más de este bendido mundo, y no me quité la vida. Me parecía andar por un trozo de paraíso, por el más maravilloso de los jardines" ${ }^{\prime 20}$.

Luego pasa a centrarse en esa íntima unión de las plantas con las tumbas que constituye aún hoy día, en su triste decadencia, uno de los mayores encantos del que fuera el primer cementerio protestante de España. No es tanto un monumento como un espacio abierto, un jardín, lo que llama la atención del escritor. En él podía dar rienda suelta a sus sentimientos románticos, a la libre asociación de ideas sinestésicas: no en vano, ese era uno de los cometidos de los camposantos de tradición anglosajona. Una sensación muy diferente a la opresión que le había producido el cementerio de Barcelona, con sus hileras

19. ANDERSEN, H.C.: Viaje..., 112.

20. Ibídem, 119-120. 
de nichos que le parecieron "un almacén lleno de cajas amontonadas con las tapas hacia fuera" ${ }^{21}$. Tanto le apasionó el Cementerio Inglés, que en su retorno a la ciudad volvió a visitarlo.

Si como poeta admira profundamente esa ciudad de los muertos, su atracción por la vitalidad urbana le lleva a dedicar un espacio similar a la descripción del Paseo de la Alameda, el centro de la ciudad de los vivos. Tanto, que en realidad no describe su trazado (tan sólo advierte, con la metáfora de Venus Anadyomene, su condición de espacio surgido sobre la playa), sino que ante todo lo que le interesa es su bullicio como salón principal de Málaga, cuando aún quedaban treinta años para la apertura de la calle Marqués de Larios, que en la última década del siglo la sustituiría como centro de la vida social. En la Alameda se enclavaba la "Fonda de Oriente", donde Andersen estuvo alojado. Situada en el actual número 8 , esquina al callejón del Comisario, ocupaba un edificio de finales del XVIII que sería reformado por el maestro de obras Eduardo Strachan en $1896^{22}$. El escritor lo define como un establecimiento moderno y cosmopolita, donde se hablaba francés y alemán (de hecho, fue atendido por un camarero berlinés) y en el que servían cerveza inglesa, algo no muy habitual en los locales españoles donde había pernocta$\mathrm{do}^{23}$. Asomado por la noche al balcón, la alegría del ambiente en el paseo, en el que incluso una banda tocaba temas del Norma de Bellini, le llevó a bajar a la Alameda, a mezclarse con la multitud: "la alegría y la juventud reinaban en todas partes. 'Málaga, hermosa ciudad, aquí me siento como en casa', pensaba yo jubiloso" 24 .

En una de las plazas principales, cuyo nombre no indica aunque sí dice que cuenta con varios cafés y comercios, el autor de Pulgarcita dio con "la estatua de una mujer muy hermosa, que sostiene en la mano alzada una antorcha; todas las noches encienden su llama" ${ }^{25}$. No conocemos ningún monumento público que responda a esta descripción exacta, por lo que debe tratarse de alguna escultura desaparecida ya hace tiempo, o alguna figura efímera instalada con motivo de la coetánea visita de Isabel II.

21. Ibídem, 43-44.

22. Archivo Municipal de Málaga (A.M.M.), Legajo 1325/8. En el siglo XX se le añadiría el ático.

23. Las fondas y hoteles de las localidades costeras sí solían poseer este carácter cosmopolita, al tener una clientela preferentemente foránea, que les llevaba a contar con bastante servicio de esas nacionalidades. Así, la "Fonda de Oriente", que en realidad era un hotel, seguía básicamente el modelo francés. RECIO MORA, R.: "Aproximación a una historia de los edificios hosteleros españoles durante los siglos XVIII y XIX”, Boletín de Arte 13-14, 1992-3, 188 y 193.

24. ANDERSEN, H.C.: Viaje..., 109.

25. Ibídem, 112-3. 
Andersen no se limita a recorrer los espacios elegantes de Málaga. A lo largo de las páginas de Viaje por España hace gala de una percepción total de las ciudades, alternando los lugares de la élite con las zonas populares e incluso algunas de las más degradadas. Y aunque hoy día nos resulte una visión bastante moderna del modo de enfrentarse al conocimiento profundo de una urbe, no debe olvidarse que los extranjeros que visitaban España solían buscar un tipismo que sólo podían ofrecerle los barrios más populares, aunque a veces acarrease un cierto peligro, que no dejaba de formar parte de la emoción viajera, ese elemento de aventura que posee cualquier desplazamiento fuera del lugar familiar. Lo que por otra parte viene a patentizar que la vertiente extremadamente pusilánime de la personalidad del autor de La niña de los fósforos, no estaba reñida, cuando se vestía de viajero, con esa otra más valiente y de espíritu ciertamente aventurero, capaz de adentrarse en lugares recónditos y fuera de las rutas habituales de su época, llegando hasta Estambul y el norte de Suecia, pese a que en su maleta siempre llevaba una cuerda por si había algún incendio ${ }^{26}$. En este caso, aunque no se trataba de lugares muy marginales ni peligrosos, visitó el cauce seco del río Guadalmedina, donde se había instalado un mercadillo, y el barrio del Perchel. Otro de sus paseos favoritos era por los muelles del puerto y la playa situada a espaldas de la Alameda.

En el éxito de su estancia malagueña resultaron decisivos sus anfitriones. Andersen fue un hombre que siempre destacó por su habilidad para establecer contactos, para relacionarse con la gente que más le convenía, con un desparpajo que no deja de sorprendernos ${ }^{27}$. Sin embargo, aunque llegó a nuestro país con varias cartas de recomendación, no surtieron los frutos deseados, con lo que su viaje le resultó bastante agridulce. España era uno de los lugares que más deseaba conocer desde que, cuando tenía tres años, causó un agradable revuelo en su Ostende natal el destacamento de soldados españoles (el Regimiento Zamora) que, bajo las órdenes francesas, llegó en 1808 para combatir contra Suecia, entonces enemiga de una Dinamarca aliada de Napoleón ${ }^{28}$. Pero tras acariciar largamente tan deseado viaje, al llegar se encontró con que su querida España no le agasajó como estaba acostumbrado, ante todo porque aquí aún no se había traducido su obra, y sólo era conocida por una minoría de lectores de origen foráneo. Y él, habituado a relacionarse en sus desplazamientos con escritores y artistas como Heine, Lamartine, Hugo, Dumas, Dickens, Thorvaldsen, Mendelssohn o Liszt, tuvo que contentarse con tratar superficialmente en España sólo al duque de Rivas y a Hartzenbusch, aparte de a algunos literatos muy menores. Su exagerada susceptibilidad se sintió

26. NIELSEN, E.: op. cit., 64.

27. Ibídem, 38.

28. ANDERSEN, H.C.: El cuento..., 60. 
dañada, cuando lo que esperaba era casi un baño de multitudes en su periplo hispano.

Por eso, su adoración por Málaga está ligada a las buenas relaciones que aquí estableció. En este sentido, resultó esencial el carácter cosmopolita de la ciudad, o por lo menos la abundancia de familias de origen extranjero que la caracterizó desde el siglo XVIII. Concretamente, Andersen trató con los más ilustres representantes de la colonia alemana: cita a los Scholtz, los Delius y los Pries. Todos ellos lo agasajaron como a él le gustaba (y como, por supuesto, sabía que se merecía), con comidas, veladas y recepciones, por lo que, en comparación con otras ciudades, Málaga hizo con largueza honor a su famosa hospitalidad. Todas esas familias eran comerciantes capitalistas, al por mayor, lo que los convertía en algunos de los malagueños más ricos de mediados de siglo ${ }^{29}$. Al primero que nombra es a Eduardo Delius Rey, entonces con 42 años y casado con María Loring (de 38), a quien se presentó con una carta de recomendación del cónsul general danés, Salomonsen ${ }^{30}$. Aunque no indica el nombre de pila, al hablar de que también conoció a su padre, evidencia que se trata obviamente de él, que en aquella fecha vivía en el número 27 de la Alameda ${ }^{31}$. De manera que Delius fue su principal introductor en la alta sociedad malagueña.

Al igual que sucedió con Delius, de las otras familias trató principalmente a sus miembros más jóvenes o de mediana edad, en su mayoría ya nacidos en Málaga. Al hablar de los Scholtz comete leves errores: indica que el Sr. Scholtz es el joven cónsul danés, que vive en la Alameda Principal, que su mujer es una sueca amiga de Jenny Lind (la célebre cantante que fue una de las íntimas amistades de Andersen, casi su alma gemela) y que tienen una hijita de cuatro años y medio llamada Trinidad. Sin embargo, analizando los padrones se descubre la confusión de Andersen. En 1862, el cónsul danés era Emilio Scholtz, berlinés de 74 años (llevaba 58 en Málaga), que vivía en el número 8 de la calle Arriola con varios sobrinos ${ }^{32}$. En cambio, el Scholtz al que se refiere el escritor es indudablemente Enrique, comerciante de 34 años nacido en Málaga, casado con Mathilde Beer (de 30), natural de Estocolmo, y con dos hijas, Trinidad (4) y Mathilde (1); su domicilio se situaba en la tercera

29. En 1859, en la lista de los cincuenta mayores contribuyentes de la ciudad, el cuarto lugar lo ocupan la sociedad Wunderlich y Pries, y el sexto la empresa de los Delius. GARCÍA MONTORO, C.: "El cuerpo social del comercio malagueño en el siglo XIX", Homenaje a D. Francisco Bejarano, Málaga 1991, 101.

30. ANDERSEN, H.C.: Viaje..., 114, n. 3.

31. A.M.M., Padrones Municipales, T. 275/1, 1862, fol. 15. Su padre era Eduardo Delius, un viudo germano de 79 años que llegó en 1822 a Málaga, y que vivía en Peligro ${ }^{\circ} 7$ (la actual calle Trinidad Grund) junto a su hermano Conrado, de 75 y casado con Paulina, de 33. Ibídem, fol. 211.

32. Ibídem, fol. 6 . 
planta del $n^{\circ} 21$ de la calle Peligro ${ }^{33}$. En los dos casos se trataba, por tanto, de calles del sector de la Alameda. Respecto a la confusión sobre el consulado, puede ser un despiste del escritor, pero también uno de los frecuentes productos de su irrefrenable vanidad: resultaba más prestigioso reseñar que uno de sus amigos malagueños era el máximo representante diplomático de su país en la ciudad sureña. No obstante, no iba descaminado: cuatro años más tarde, en 1866, Enrique ya era el cónsul de Dinamarca ${ }^{34}$. En cuanto a Pries, se trataba de Adolfo, de 42 años, comerciante nacido en Rostock y casado con Francisca Scholtz, de 30 (por lo tanto, era cuñado de Enrique), que con sus dos hijos, Clara (9) y Adolfo (4), vivían en el $n^{\circ} 7$ de la ya desaparecida calle San Juan de Dios, en el sector de la actual Molina Lario ${ }^{35}$. Junto a Wunderlich, dirigía una de las sociedades comerciales más potentes de Málaga.

Andersen también visitó las villas de dos miembros de la familia Delius: la de Eduardo y la de su padre. La primera se ubicaba Guadalmedina arriba, mientras que la segunda estaba en Teatinos, pese a que el danés la sitúa en la zona oriental, junto a la carretera de Almería. Y en ambos casos, el escritor se centra en los jardines: su poder evocador le ofrece más sugerencias que la arquitectura, del mismo modo que en Granada prefería pasear por el Generalife que por la Alhambra. El jardín de Eduardo Delius se disponía escalonado en terrazas. Además, Delius padre era botánico, por lo que había convertido su quinta en un esplendoroso vergel tropical. También, de regreso de la hacienda del hijo, visitarían una quinta abandonada, con unas grandes cisternas para la recogida del agua de lluvia.

Según indica Andersen, en la hacienda del padre de Delius sería recibida por las autoridades locales Isabel II, con motivo de su visita a Andalucía y Murcia, que coincidió con la estancia del danés por estos lares. Efectivamente, el día 16 de octubre (Andersen estaba entonces en Granada) la reina y Francisco de Asís hicieron su primera parada en esa finca, adornada para la ocasión y en la que se les ofreció el carruaje oficial; a cambio, los monarcas regalaron al alemán una cadena de reloj ${ }^{36}$. En Viaje por España describe las galas de la ciudad ante la llegada de la reina, como las lámparas de la Catedral, las fuentes de la Alameda, los arcos de triunfo instalados en varias calles y el quioscoembarcadero neoárabe del muelle. Días antes de que arribara Isabel a Málaga (la reina estuvo aquí entre el 16 y el 19 de octubre), el escritor fue espectador del recibimiento triunfal en Granada, un hecho que también le causó malestar:

33. Ibídem, fol. 212v.

34. MERCIER, A. y DE LA CERDA, E.: Guía de Málaga y su provincia. Cádiz 1866, 275.

35. A.M.M., Padrones Municipales, T. 275/1, 1862, fol. 268v.

36. CAMACHO MARTÍNEZ, R.: "El poder de la fiesta. Algunos apuntes sobre las celebraciones de Isabel II en las provincias de Andalucía y Murcia en 1862”. Introducción a la ed. facsímil de FRANQUELO, R.: La Reina en Málaga. Málaga 1991 (1862), XXIV y XXXVI. 
acostumbrado a ser recibido por monarcas de toda Europa, estaba deseoso por conocer a la Borbón. Sin embargo, no pudo ser, y tuvo que contentarse con verla pasar desde el jardín de una baronesa. Para colmo de males, en la ciudad del Darro enfermó junto a Jonas, quien por otra parte pronto chocó con Andersen a causa del complicado carácter de un escritor con quien era muy difícil convivir largo tiempo: éste no lo dice en el libro (de hecho, apenas cita a su compañero, lo cual también es sintomático), pero sí en su diario ${ }^{37}$. El caso es que, sin especificar en exceso los motivos, hay una frase bien significativa de sus sentimientos hacia la urbe: "Granada, con toda su magnificencia y belleza, fue la ciudad española que me dejó más de un recuerdo amargo y doloroso" 38 . El mal sabor de boca granadino, pese al reconocimiento de su monumentalidad, permitió la idealización de una Málaga a la que regresó con sumo gusto. Incluso aquí seguirían las repercusiones de sus desencantos, ya que en Málaga, en el momento de hacer su equipaje para partir en barco hacia Gibraltar, advirtió la pérdida de una de sus más queridas condecoraciones, los mejores exponentes de su vanidad: "La Estrella del Norte", que le había regalado el importante literato danés Adam Oehlenschläger. Pese a que Eduardo Delius puso anuncios en la prensa local, las pesquisas resultaron inútiles, y Andersen tuvo que regresar a su país sin la medalla que distinguía a los caballeros de la Orden de Nordstjernen ${ }^{39}$.

Salvo este contratiempo, en Málaga, al igual que hizo en la mayoría de las ciudades en las que permaneció más de una semana, tuvo tiempo para el ocio cultural. La misma tarde de su primera partida, antes de tomar la diligencia hacia Granada, Andersen acudió a una corrida de toros cuya violencia le desagradó enormemente (en Barcelona había asistido a una novillada bastante incruenta): "me causó una impresión convulsiva e inolvidable" ${ }^{40}$. Los diestros fueron El Salamanquino y Bocanegra, estando bastante más afortunado este último ${ }^{41}$. Hay que indicar que el coso no era el de La Malagueta, inaugurado en 1876, sino el que el promotor Antonio María Álvarez había levantado en 1840 en la zona de la Goleta, y que duraría hasta 1864.

37. REY, M.: op. cit., 350.

38. ANDERSEN, H.C.: Viaje..., 184.

39. Ibídem, 183-4. Nuestras indagaciones en la prensa local han sido infructuosas al respecto.

40. Ibídem, 123.

41. El Avisador Malagueño, 7-10-1862, 4. Se lidiaron a partir de las 14 horas ocho toros de la ganadería de Anastasio Martín, de Coria del Río. Los espadas anunciados en un primer momento eran Manuel Domínguez y Manuel Fuentes, Bocanegra. Ibídem, 1-10-1862, 4. Sin embargo, el mismo día de la corrida se supo que Domínguez, que había sufrido una cogida en otra plaza, sería sustituido por Julián Casas, El Salamanquino. Ibídem, 5-10$1862,4$. 
También aprovechó su segunda estancia malagueña para ir a la ópera: una representación de Martha de Friedrich von Flotow en el Teatro Principal (el Teatro Cervantes no se inauguraría hasta 1870). Andersen dice que acudió al estreno, por lo que tuvo que ser el jueves 23 de octubre, fecha para la que se anunciaba la primera función de una "grandiosa ópera nueva", que estuvo en cartel hasta el domingo $26^{42}$. La función era a las 19,30, y la entrada de diario costaba 5 reales, mientras que la de los domingos ascendía a 6. En un aforo con poco público (que dice mucho sobre la cultura de la sociedad malagueña del XIX), pudo disfrutar de unas buenas interpretaciones, pese a que los decorados "eran una miseria" y a que hubiera preferido una obra de Mozart ${ }^{43}$. También indica que en el comienzo de la temporada se representaron tres óperas de Verdi: Rigoletto, La Traviata y Un ballo in maschera.

De la estancia de Andersen en Málaga no sólo queda el hermoso testimonio de sus palabras. La ciudad, que se enorgullece de haber tenido entre sus ilustres visitantes al autor de La campana, ha erigido en las últimas décadas dos remembranzas públicas de su paso en 1862. En octubre de 1987, la comunidad danesa de la ciudad colocó una placa cerámica obra de Amparo Ruiz de Luna en el edificio donde se situó la "Fonda de Oriente", en la que se reproducen las palabras elogiosas de Andersen con las que comenzamos el artículo. En junio de 2005, con motivo del bicentenario de su nacimiento, el Ayuntamiento ha instalado en la Acera de la Marina un monumento al escritor, obra de José María Córdoba, de nuevo gracias al patrocinio danés ${ }^{44}$. Se trata de una escultura de bronce que se encuadra en la tendencia, muy extendida actualmente, de la integración en el paisaje urbano, del diálogo directo con el viandante: Andersen aparece sentado en un banco de acero vestido de viaje y con una bolsa por la que asoma el patito feo ${ }^{45}$. Con su alter ego el futuro cisne, Hans Christian Andersen estará eternamente en su querida Málaga, disfrutando de su clima, de su mar y de sus gentes, aun a costa de sufrir con paciencia los inevitables inconvenientes de las palomas.

42. El Avisador Malagueño, 22-10-1862, 4 y 26-10-1862, 4.

43. La soprano era polaca, el tenor ruso y el resto de los cantantes, italianos. ANDERSEN, H.C., Viaje..., 181-2. La prensa anunciaba: "En los actos primero y cuarto caerá el telón de boca instantáneamente para variar la escena". El Avisador Malagueño, 24-10-1862, 4.

44. Como se indica en una placa, la actuación fue patrocinada por la Fundación Reina Isabel de Dinamarca, Novo Nordisk, Widex Audífonos y Defco, e inaugurada por la princesa Benedikte.

45. Una excelente lectura del monumento, en: SÁNCHEZ LÓPEZ, J.A.: La voz de las estatuas. Escultura, arte público y paisajes urbanos de Málaga. Málaga 2005, 589-592. 
